\title{
Margaret McCartney: Just enough medicine for all
}

\author{
Margaret McCartney general practitioner, Glasgow
}

This summer I swam in the Baltic and learnt the word lagom. This Swedish word is hard to translate: it means "just right" - not too much and not too little. It also has echoes of fairness, neither ostentatious nor sparse.

It is not to do with perfection. An etymological translation is "around the team"- that is, enough for everyone to get a fair share. It's why our rented house had space in the cupboards, room on the shelves, and unencumbered space in which to play. Medicine has lost this balance. We persistently hear that earlier diagnosis is better diagnosis, even if testing at an earlier stage incurs anxiety because of more false positives. We are alerted to the risks from cholesterol and blood pressure, and we are told that diagnosing stage 3 chronic kidney disease is a good thing, even if it is the risk factor that renders someone's holiday insurance unaffordable.

The use of time as a diagnostic tool- that ancient craft in the practice of medicine-is evaporating as we fear missing a rare but important diagnosis. Thus we proceed to more tests, many of which will be unnecessary and a few of which will incur unintended harmful consequences.

In the meantime, what happens in the consulting room? As Osler said a hundred years ago, listen, for the patient is telling you the diagnosis. Patients come in with stories of what happened, when, and with whom; with questions of what is wrong, what might be done, and what might happen; and yet we interrupt after half a minute. ${ }^{1}$ Getting to know the people for whom I am a GP fuels my professional pride, but the pressure on appointments is immense-even before the house calls, results, and paperwork that each day demands.
The NHS should be primarily a "national sickness service" for people with symptoms, who are suffering and who are afraid of what their illness means. Giving diagnoses to asymptomatic people who "might" go on to develop dementia, for example, uses up time and cash. However, when we listen to the relatives of someone who has recently had dementia diagnosed, the lack of support is clear. The flip side of overdiagnosis and overtreatment is insufficient care for others.

We have limited resources; who would benefit most from them? Currently, the NHS is unfair. It's topsy-turvy. It lacks lagom.

Competing interests: I have read and understood the BMJ policy on declaration of interests and declare the following interests: I'm an NHS GP partner, with income partly dependent on Quality and Outcomes Framework points. I'm a part time undergraduate tutor at the University of Glasgow. l've written a book and earned from broadcast and written freelance journalism. I'm an unpaid patron of Healthwatch. I make a monthly donation to Keep Our NHS Public. I'm a member of Medact. I'm occasionally paid for time, travel, and accommodation to give talks or have locum fees paid to allow me to give talks but never for any drug or public relations company. I was elected to the national council of the Royal College of General Practitioners in 2013.

Provenance and peer review: Commissioned; not externally peer reviewed.

Follow Margaret McCartney on Twitter, @mgtmccartney

1 Richards T. Listen to patients first. BMJ 2014;349:95765

Cite this as: BMJ 2014;349:96421

○ BMJ Publishing Group Ltd 2014 